\title{
Interfacing sleep and aging
}

\author{
Ahmed BaHammam ${ }^{1 *}$ and S.R. Pandi-Perumal ${ }^{2}$ \\ 1 The University Sleep Disorders Center, Department of Medicine, College of Medicine, King Saud University, Riyadh, Saudi Arabia \\ 2 Somnogen Inc., Toronto, ON, Canada \\ *Correspondence: ashammam2@gmail.com
}

"Ageing seems to be the only available way to live a long life"

- Daniel Francois Esprit Auber

Sleep disruption is one of the most challenging problems occurring with advancing age and additionally represents the most frequently expressed health complaint among the elderly (Monjan, 2007). Despite the ubiquity of the problem in modern times, disturbed sleep may not have always been a significant health problem, and it is possible that prehistoric man suffered neither the frequency nor intensity of sleep disruption that is so commonly reported today. Evidence suggests that man's lifetime was much shorter during the Paleolithic, Mesolithic, and early Neolithic periods, averaging only about $30-40$ years (Thorpy, 2001). It would thus appear that in addition to the benefit of an extended lifespan, which in large measure has been provided by medicine and technology, one of the health costs of living in modern times is the gradual reduction in sleep quality which man experiences as he ages. The field of sleep medicine has developed considerably over the last 50 years, with dramatic improvements being seen in the diagnosis, treatment, and management of sleep disorders (Shah et al., 2006). Sleep is very often considered to be a barometer of health and as we age, the parallel increases in chronic diseases (medical and psychiatric comorbidities) various stressors, and increased consumption of medications, tend to take a toll on the quality of sleep we experience. Thus as we age we begin to experience a tradeoff between the benefits having a longer life, while concurrently the quality of our lives may be decreasing. Without a doubt, the modern medical advances to which we have access today are the results of decades of investment in medical research. As we age, we also learn to live with such inconveniences of modern life despite the fact the society is driven by the development of science and technology. That is the reality of life.
Obviously there are challenges ahead. Sleep disorders are highly prevalent in the general population, and not only represent direct personal health problem, but indirectly affect health by increasing the risk of accidents which can bring harm to the affected individual as well as to those around him (Institute of Medicine Report, 2006; Pandi-Perumal et al., 2006). Up to $50 \%$ of older persons in Western societies complain of sleep disturbances, including the quality and quantity of sleep (e.g., frequent awakenings, disturbances to the sleep/wake cycle, and daytime sleepiness) (Vitiello, 2006). Aging is further characterized by modifications of morphology, quality, and quantity within the $24 \mathrm{~h}$ sleep/wake architecture. Sleep specialists continue to debate whether or not older individuals need less sleep. Despite the many efforts to resolve this problem, the question remains: what are the ideal characteristics of "normal" sleep in the elderly. Studies have shown that the ability to sleep decreases with age (Pandi-Perumal et al., 2002; Ancoli-Israel, 2009). This raises the following question: Is this reduction in sleep ability a natural part of aging or does it result from other comorbid conditions that develop as people age? Collectively, published studies support the view that sleep disturbances are not directly related to age. Sleep complaints in older adults are often associated with medical and psychiatric comorbidities rather than the fact of aging itself (Vitiello et al., 2002; Foley et al., 2004). In the absence of comorbidities, older adults usually have few changes in sleep characteristics. Poor sleep in the elderly is a major health problem because it has been linked to serious consequences including poor physical and mental health (Paudel et al., 2010). Poor sleep may be associated with the prodormal phase of a disease, as a prominent complaint and/or exacerbation of the symptoms of a particular disease. A significant association between poor sleep and falls has been confirmed by a number of studies (Avidan et al., 2005; Stone et al.,
2008). In addition, a significant association between sleep disturbances and increased mortality in the elderly has been reported (Dew et al., 2003; Paudel et al., 2010). Therefore, it is very important to recognize and treat sleep disturbances and the associated medical and psychiatric disorders in this group of patients (Avidan and Alessi, 2008; Pandi-Perumal et al., 2010; Pigeon and Matteson-Rusby, 2010).

In this issue of Frontiers in Sleep and Chronobiology, Monjan presents his views on what direction sleep research in the elderly will take in the future and reviews recent data that are related to specific sleep disorders and their consequences; these disorders include insomnia, sleep disordered breathing (SDB), restless legs syndrome, circadian rhythm problems, and metabolic changes that are secondary to sleep deprivation (Monjan, 2010). Although the prevalence of SDB is common among people aged 65 years and older, there are mixed opinions among sleep experts about whether SDB in this population is equivalent to SDB in middle-aged people (Stone and Redline, 2006). The metabolic consequences and impact of SDB on cognitive functioning are major issues. Additionally, the effect of SDB on end organs, such as those of the cardiovascular system, may differ in the elderly when compared to younger patients, and this is another topic which is of considerable research interest. Despite the debate on the effect of SDB on morbidity and mortality in the elderly, older adults with symptoms of $\mathrm{SDB}$, or with comorbidities that are associated with SDB, should be evaluated and considered for treatment. Monjan also shows that neuronal loss is not an inevitable consequence of aging and states that age-related changes in the control of sleep appear to be related to subtle changes within neurons and in their interactions with other brain cells. He reviews recent data which indicate that factors such as adenosine may be important for regulating the sleep homeostatic process. $\mathrm{He}$ further concludes that such discoveries may lead to the development of more effective and targeted pharmacological approaches 
to some of the sleep problems that affect the elderly population. The author also discusses recent data on sleep and metabolism that address the relationship between sleep duration and obesity in the elderly. In addition, his article reviews the literature on sleep and cognition and discusses the proposed molecular mechanisms that underlie the relationship between sleep and long-term memory. Further, his contribution identifies and reflects the critical role of reduced social and physical activity as contributing factors to sleep problems and cognitive changes in older nursing home residents. Indeed, the article by Monjan appropriately suggests that simple social modifications can positively impact sleep and neuropsychological function in this group. The consideration of this range of basic and applied clinical issues is reflective of the increasingly interdisciplinary and multidisciplinary nature of research in sleep medicine.

In the coming years, the increasing proportion of the population which will be reaching advanced age (e.g., as a result of medical breakthroughs and pharmaceutical suppression of aging), as well as the pressures of our modern $24 \mathrm{~h}$ society, all point to the possibility that the research challenges that we will be facing will be increasing. Hopefully, among many other factors, innovative molecular biotechnological tools such as genomics, epigenetics, and proteomics will enable us to effectively meet these challenges. Integration of such techniques will hopefully foster innovative approaches for the screening, diagnosis, and management of sleep disorders in the elderly.

\section{REFERENCES}

Ancoli-Israel, S. (2009). Sleep and its disorders in aging populations. Sleep Med. 10(Suppl. 1), S7-S11.

Avidan, A. Y., and Alessi, C.A. (eds). (2008). Geriatric Sleep Medicine. New York, USA: Informa Healthcare, 261.

Avidan, A. Y., Fries, B. E., James, M. L., Szafara, K. L., Wright, G. T., and Chervin, R. D. (2005). Insomnia and hypnotic use, recorded in the minimum data set, as predictors of falls and hip fractures in Michigan nursing homes. J. Am. Geriatr. Soc. 53, 955-962.

Dew, M. A., Hoch, C. C., Buysse, D. J., Monk, T. H., Begley, A. E., Houck, P. R., Hall, M. S. H., Kupfer, D. J., and Reynolds, C. F. (2003). Healthy older adults' sleep predicts all-cause mortality at 4 to 19 years of follow-up. Psychosom. Med. 65, 63-73.

Foley, D., Ancoli-Israel, S., Britz, P., and Walsh, J. (2004). Sleep disturbances and chronic disease in older adults: results of the 2003 National Sleep Foundation Sleep in America Survey. J. Psychosom. Res. 56, 497-502.

Institute of Medicine Report. (2006). "Sleep disorders and sleep deprivation: an unmet public health problem,” in Committee on Sleep Medicine and Research, eds H. R. Colten and B. M. Altevogt (Washington, DC, USA: The National Academies Press), 424.

Monjan, A. (2010). Perspective on sleep and aging. Front Neur. 1:124. doi: 10.3389/fneur.2010.00124.

Monjan, A. A. (2007). "Sleep in aging," in Sleep Disorders: Their Impact on Public Health, eds D. Leger and S. R. Pandi-Perumal (Abingdon, Oxon: Informa Healthcare), 59-65.

Pandi-Perumal, S. R., Monti, J. M., and Monjan, A. A. (eds). (2010). Principles and Practice of Geriatric Sleep Medicine. Cambridge, England: Cambridge University Press, 448.

Pandi-Perumal, S. R., Seils, L. K., Kayumov, L., Ralph, M. R., Lowe, A., Moller, H., and Swaab, D. F. (2002). Senescence, sleep, and circadian rhythms. Ageing Res. Rev. 1, 559-604.

Pandi-Perumal, S. R., Verster, J. C., Kayumov, L., Lowe, A. D., Santana, M. G., Pires, M. L. N., Tufik, S., and Mello, M. T. (2006). Sleep disorders, sleepiness, and traffic safety: a public health menace. Braz. J. Med. Biol. Res. 39, 863-871.

Paudel, M. L., Taylor, B. C., Ancoli-Israel, S. Blackwell, T., Stone, K. L., Tranah, G., Redline,
S., Cummings, S. R., and Ensrud, K. E. (2010). Rest/activity rhythms and mortality rates in older men: MrOS Sleep Study. Chronobiol. Int. 27, 363-377.

Pigeon, W. R., and Matteson-Rusby, S. (2010). "Sleep in late-life depression,” in Sleep and Mental Illness, eds S. R. Pandi-Perumal and M. Kramer (Cambridge, England: Cambridge University Press), 173-182.

Shah, T. R., Trajanovic, N., and Shapiro, C. M. (2006). "Assessment and treatment of sleep disturbances in aged population," in Clinical Pharmacology of Sleep, eds S. R. Panid-Perumal and J. M. Monti (Basel, Switzerland: Birkhauser-Verlag), 153-172.

Stone, K. L., Ancoli-Israel, S., Blackwell, T., Ensrud, K. E., Cauley, J. A., Redline, S., Hillier, T. A. Schneider, J. Claman, D., and Cummings, S. R. (2008). Actigraphymeasured sleep characteristics and risk of falls in older women. Arch. Intern. Med. 168, 1768-1775.

Stone, K. L., and Redline, S. (2006). Sleep-related breathing disorders in the elderly. Sleep Med. Clin. 1, 247-262.

Thorpy, M. J. (2001). "History of sleep and man," in The Encyclopedia of Sleep and Sleep Disorders (Facts on File Library of Health and Living), eds M.J. Thorpy and J. Yager (New York, USA: Facts On File, Inc.), ix-xxx.

Vitiello, M. (2006). Sleep in normal aging. Sleep Med. Clin. 1, 171-176.

Vitiello, M. V., Moe, K. E., and Prinz, P. N. (2002). Sleep complaints cosegregate with illness in older adults: clinical research informed by and informing epidemiological studies of sleep. J. Psychosom. Res. 53, 555-559.

Received: 13 September 2010; accepted: 13 September 2010; published online: 12 November 2010.

Citation: BaHammam A and Pandi-Perumal SR (2010) Interfacing sleep and aging. Front. Neur. 1:132. doi: 10.3389/fneur.2010.00132

This article was submitted to Frontiers in Sleep and Chronobiology, a specialty of Frontiers in Neurology.

Copyright ( $\odot 2010$ BaHammam and Pandi-Perumal. This is an open-access article subject to an exclusive license agreement between the authors and the Frontiers Research Foundation, which permits unrestricted use, distribution, and reproduction in any medium, provided the original authors and source are credited. 